\title{
A Reason to Know
}

\section{Olof Leffler ${ }^{1}$ (1)}

Accepted: 16 July 2021

(C) The Author(s) 2021

According to desire-based versions of reasons internalism, roughly yet famously, an agent $A$ has a reason to $\varphi$ just in case she or her idealized counterpart desires to $\varphi .{ }^{1}$ Unless further assumptions are made, it therefore seems like the reasons an agent has vary with their desires. For example, on Williams' paradigmatic version of the view, an agent's reasons must be such that they can be arrived at using a sound deliberative route from her present motivational set. But what such sets contain can vary enormously, so it seems like reasons can too (Williams, 1981).

Much of the debate surrounding desire-based reasons internalism has, understandably, focused on whether it can capture moral reasons well. Contra authors like Williams, it has often been argued that desire-based reasons internalism suitably understood in fact entails moral conclusions (e.g. Lindeman, 2019; Markovits, 2014; Smith, 1994; 2011; 2012; 2020; cf. Brunero, 2017; Bukoski, 2016; Joyce, 2001 for criticism). I do not aim to take a stand on this debate here.

This is because whatever we make of the arguments for or against moral reasons, there is another question which lurks in the background: namely, what exactly are the commitments of desire-based reasons internalism? This question is much broader than the question of whether the view entails moral reasons. In particular, the question of whether there might be categorical reasons (in the sense of reasons which are shared by all) irrespectively of whether these count as moral reasons has not received much attention - even though desire-based reasons internalism has been a prominent account of reasons in the literature for decades. It would therefore be a remarkable upshot if desire-based reasons internalism would turn out to be committed to such reasons. To gain a fuller understanding of what desire-based reasons internalism commits us to, then, we ought to explore whether it commits us to such reasons. ${ }^{2}$

\footnotetext{
1 Some, though by no means all, prominent defences are: Joyce (2001), Lindeman (2019), Markovits (2014), Schroeder (2007), Smith (1994; 1995; 2011; 2012; 2020), Street (2008), Williams (1981).

2 Following Smith (1994), some have discussed whether the desires of ideal agents would converge to generate categorical reasons - Hubin (1999) and Joyce (2001) are particularly strong critics in my view (though cf. Smith, 2011; 2012; 2020). But this debate does not touch on specific non-moral possibilities.
}

Olof Leffler

olof.leffler@durham.ac.uk

1 Department of Philosophy, Durham University, 50/51 Old Elvet, Durham DH1 3HN, UK 
I aim to go some way towards doing so in this paper. Taking unexpected cues from Michelle Kosch's recent work on J.G. Fichte (Kosch, 2015; 2018), I shall argue that desire-based reasons internalism, suitably understood, is committed to at least one categorical reason - and it does not rule out that there could be others. The reason I shall defend is a (practical) reason to obtain or maintain knowledge about our surroundings. Using Fichte's insights and some standard desire-based reasons internalist assumptions, my strategy shall be to argue that all ideal agents the desires of which explain reasons are committed to desiring such knowledge. As reasons internalism, suitably understood, takes our reasons to depend on their desires, it follows that all agents have such a reason. This reason counts as an internalist-style categorical reason, but it is not obvious whether it has anything to do with morality.

To show this, I start in section (1) by outlining Kosch's Fichte. In section (2), I raise some problems for the constitutive aims she attributes to him. In section (3), I argue that the main insights in the argument for them can be coopted in a reasons internalist framework, generating the conclusions just mentioned. In section (4), I evaluate whether the reason I have defended is a moral reason and argue that it is unclear whether it is one. I conclude in section (5).

\section{Kosch's Fichte}

In recent work, Michelle Kosch has reconstructed Fichte's moral philosophy and differentiated it from Kant's, making his innovations stand out. My aim is, however, to incorporate some of Fichte's moves into an even more contemporary debate. That means that I shall not be concerned with historical accuracy, so I want to state immediately that I am more interested in Kosch's Fichte than in Fichte himself. Whether or not the rendition of his view I discuss is historically accurate is a question I will leave to others to answer. Nevertheless, I shall refer to Kosch's Fichte as just 'Fichte' from here and on.

Fichte takes independence to be of central concern in both the philosophy of action and ethics. More specifically, he thinks that there are several constitutive aims of agency, meaning that there are several things agents aim at, and are agents in virtue of aiming at. ${ }^{3}$ The first aim is formal independence, which is perfection in the exercise of the disposition to set ends on the basis of concepts of ends through the activity of rational reflection (Kosch, 2018, ch. 4; cf. p. 152). That is a complicated way of saying that it is constitutive of agency to set ends (including forming plans or intentions) that the agent aims to live up to by reflecting on what to do.

However, agency also has the aim of material independence. ${ }^{4}$ An action lives up to this aim when it is part of a series of actions in the limit of which one would 'arrive at the state of absolute freedom from all limitation' (Kosch, 2018, p. 39; cf. Fichte, 1798). What does that mean? Fichte seems to think that freedom from

\footnotetext{
${ }^{3}$ For more on the notion of constitutive aims, see Katsafanas (2013, ch. 2; 2018).

4 The 'formal/material' distinction here is obscure, but nothing in my argument turns on it, so it can be ignored for now.
} 
limitation is a telos of action the satisfaction of which one should maximize, and consequently that actions are better (or worse) to the extent that they live up to it or fail to do so.

Here, Fichte seems to claim that a formal notion of independence, as encapsulated in his first constitutive aim, is not action-guiding. One can live up to that aim and still act in pretty much any way. However, the rational self has many properties of its own, and these set limitations on how one may act. ${ }^{5}$ Independence for the rational self, qua rational self, grounds three types of duties which are conducive to its material independence. These are duties concerning the preservation and development of its physical power, of its intellect, and of coordinating its own and others' activities.

It is unclear whether all this hangs together or is plausible. But regardless of what we make of Fichte's framework in general, he seems committed to taking the aim of 'an environment secured against unpredictable, powerful forces of nature' (Kosch, 2018 , p. 158) to be a sub-aim of the aim of material independence. That is what matters here.

More specifically, Fichte argues:

(1) An agent who aims to exercise her capacity rationally to set ends ought (ceteris paribus) to aim to obtain or maintain any conditions necessary for the exercise of that capacity.

(2) Possession of knowledge concerning causal regularities and concerning the disposition of items in the environment is a condition necessary for the exercise of the capacity rationally to set ends.

(3) An agent who aims to exercise her capacity rationally to set ends ought (ceteris paribus) to aim to obtain or maintain of knowledge concerning causal regularities and concerning the disposition of items in the environment $(1,2)$.

(4) An environment secured against intervention by unpredictable, powerful forces uniquely facilitates the acquisition of knowledge concerning causal regularities and concerning the disposition of items in the environment.

(5) An agent who aims at acquiring knowledge concerning causal regularities and concerning the disposition of items in the environment ought (ceteris paribus) to aim to obtain or secure any conditions uniquely facilitating its acquisition.

(6) An agent who aims at acquiring knowledge concerning causal regularities and concerning the disposition of items in the environment ought (ceteris paribus) to aim to obtain or maintain an environment secured against intervention by unpredictable, powerful forces $(4,5)$.

\footnotetext{
5 These are: (i) the rational agent must be conscious of itself, (ii) it must have a nature, which is a system of drives, (iii) it must see itself as efficacious as a natural cause, so it must have a body which can be set in motion by its will, (iv) it has a drive towards independence, which only can be set in motion through the body, and as such the sustenance and perfection of the body are moral aims, $(v)$ the reflecting 'I' must be an intellect, and hence the sustenance and perfection of it qua intellect is a similar aim, ( vi) it is of limited external freedom due to its interaction with others, and others are also driven to independence, so its own drive towards it is limited by others' similar aim (Kosch, 2018, ch. 2; p. 53).
} 
(7) An agent who aims to exercise her capacity rationally to set ends ought (ceteris paribus) to aim to obtain or maintain an environment secured against intervention by unpredictable, powerful forces $(3,6)$.

(8) Every rational agent aims to exercise her capacity rationally to set ends.

(C) Every rational agent ought (ceteris paribus) to aim to obtain or maintain an environment secured against intervention by unpredictable, powerful forces $(7,8)$.

This argument is taken verbatim from Kosch (2018, pp. 158-159). ${ }^{6}$ It is quite complex and needs explication to make more sense. Premises (3), (6), (7) and the conclusion follow from other premises, but how are we to understand or motivate the others?

Premise (1) is formulated in terms of '[a]n agent who aims to exercise her capacity rationally to set ends' (Kosch, 2018, p. 159). That is another way to speak of the capacity of formal independence which Fichte takes to be constitutive of agency, as described above. Fichte thinks that if agents have that constitutive capacity and are instrumentally rational in the sense that they take necessary means to their ends, they are committed to the consequent of the premise, i.e. 'to aim to obtain or maintain any conditions necessary for the exercise of that capacity.' This is because the consequent specifies the necessary means they must take to exercise their formal constitutive aim of rationally setting ends. ${ }^{7}$

Premise (2) reads: 'Possession of knowledge concerning causal regularities and concerning the disposition of items in the environment is a condition necessary for the exercise of the capacity rationally to set ends.' It is supposed to be an expression of 'the claim that empirical knowledge is required for the exercise of practical reflection that is part of rational agency' (Kosch, 2018, pp. 159-160).

How come? Kosch - Fichte does not seem to put this point in the same way (Kosch, 2018, pp. 22-24) - argues that it is impossible to intentionally perform an action one does not have any idea about how to perform or aim at an end one has no idea about how to pursue. It follows that it is necessary to have at least some level of knowledge about one's environment to form plans. Kosch is aware that these claims about the relation between intention-formation and knowledge are controversial, however, and therefore also supplies some additional reformulations of them. ${ }^{8}$ These reformulations need not concern us yet, however - I shall return to this argument below.

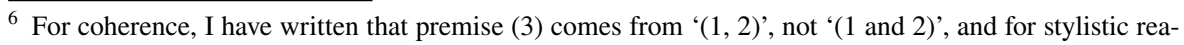
sons, her '(9)' is my '(C).'

${ }^{7}$ At least, this is the case on a narrow-scope interpretation of instrumental rationality, but the agent seems committed to the consequent even if instrumental rationality should be understood in a wide-scope manner. Giving up the capacities which are constitutive of agency rather than aiming to obtain or maintain the conditions which are necessary for its exercise is hardly a serious option for the agent.

${ }^{8}$ Most importantly, she thinks one may reformulate the premise in terms of 'true beliefs' rather than 'knowledge' (Kosch, 2018, p. 160).
} 
Instead, we reach premise (4). It reads: 'An environment secured against intervention by unpredictable, powerful forces uniquely facilitates the acquisition of knowledge concerning causal regularities and concerning the disposition of items in the environment.' Why should we think this? Fichte seems to think that 'an environment secured against unpredictable forces is required for an agent to have knowledge of the means at her disposal in any given instance of practical deliberation' (Kosch, 2018, p. 161). This is because an environment so secured allows the agent to increase the reach of her practical deliberation. In an insecure environment, the agent may have the means to her ends taken away from her while she acts, so she cannot enact the plans she aims to perform. On the other hand, in a secure environment, the agent is able to formulate and execute increasingly complex plans, freeing her from external limitations (as per the aim of material independence).

Fichte uses considerations like the one just mentioned to justify the institution of property (Kosch, 2018, pp. 75-77), but Kosch expands on his points and generalizes them to causal knowledge in general, whether or not it is related to property. However, she also departs from Fichte's considerations in two ways to generate (4) as it stands here.

First, she denies that a secure environment is 'required' - or a necessary condition - for the relevant kind of knowledge, instead preferring the language of 'unique facilitation.' This is for two reasons. First, even Fichte seems to allow that it is not necessary for us to counteract natural forces when we act. If we know enough about them, we can plan around them. For example, instead of using a mosquito net to counteract mosquito bites, we can (in principle) avoid sleeping in places where mosquitos risk biting us. Hence, it is not necessary for us to secure our environment against mosquito bites. Second, we do not need full control of our environment to learn about it. Sometimes just observing it is enough. It follows that a secure environment is not necessary for knowledge, though it does - Kosch thinks - uniquely facilitate it.

Moreover, Kosch also argues that we need general knowledge of our environment rather than knowledge which merely would enable us to act at the present moment. To defend this claim, she first agrees with writers like Nagel (1970) and Parfit (1984) that we should not privilege our present deliberation over our future deliberation. Our temporal location makes no difference. Second, she adds that deliberation can be creative and involves making increasingly complex plans over time. If so, we need more knowledge than what we have at present. With these points and some other Fichtean premises, she formulates an argument for (4) as she states it herself - but we do not need to be concerned with the exact details of that argument here.

Premise (5) is another application of the instrumental principle. The premise reads: 'An agent who aims at acquiring knowledge concerning causal regularities and concerning the disposition of items in the environment ought (ceteris paribus) to aim to obtain or secure any conditions uniquely facilitating its acquisition.' The idea here is that acquiring knowledge concerning causal regularities and dispositions of items in the environment is uniquely facilitated by the conditions that facilitate it, so one ought to attain it by instrumental rationality (Kosch 2018, p. 159).

Finally, premise (8) is the last controversial premise. It reads: 'Every rational agent aims to exercise her capacity rationally to set ends.' Kosch claims that she 
'[has] nothing to say in defense of (8) that goes beyond the defenses already abundant in the contemporary Kantian literature' (Kosch, 2018, p. 159). It would be nice to know which defences Kosch has in mind here, but I will not push this point. We can assume (8) for now, for the problems I shall identify for Fichte's argument come earlier.

\section{Problems for the Controversial Premises}

I have now explicated Fichte's argument for why security from unpredictable and powerful forces of nature is constitutive of agency. But is it plausible? I shall emphasize problems for two premises that, later, shall lead to my reformulation of the argument. They are premises (1) and (4). In the next section, I shall argue that (1) may be reformulated to avoid the problems I shall present for it. However, the problems for (4) seem to me decisive, so I shall not discuss the remaining premises after I have dealt with (4).

Let us start with premise (1). Here, as mentioned, Fichte appeals to '[a]n agent who aims to exercise her capacity rationally to set ends.' This is his understanding of the formal constitutive aim of agency. The first problem with this capacity is that it is unclear why an agent (or even a rational agent) would have to (or have to aim to) exercise her capacity to set ends to be an agent (or a rational agent). This looks like a kind of overintellectualization. Agents need not engage in deliberation to set their ends. And if it is not constitutive of agency, rational or not, to have such a capacity, Fichte's argument does not hold for all relevant agents.

Why is Fichte overintellectualizing? Some ends seem to occur naturally - desires for food, drink, sleep, pleasure, and what have you plausibly just stem from our biological hardwiring. Such desires can plausibly feature in plans, intentions, aims, ends, and similar without us having to do any cognitive work to reach them. ${ }^{9}$ Hence, there is no need to appeal to any rational or reflective end-setting capacity to generate the ends that an agent may have. Hence, it is not constitutive of agency to set ends.

Perhaps Fichte could reply by trying to interpret these ends as 'mere inclinations' or 'brute desires' or something like that, where they do not quite qualify as ends, in his sense, whatever else that involves. But that is hardly plausible for all our actual ends. The desires for food, drink, sleep, and pleasure are hardly 'mere' or 'brute' in any sense according to which they count as less important than more cognitively refined ends - if any ends are common among humans, these are. Hence, they plausibly count as ends, or at least the bases out of which we unproblematically form ends, without the need for any cognitive or rational machinery. Again, Fichte seems to overintellectualize our end-setting.

A second problem for premise (1) is that even granting that agents have a rational capacity to set ends, the exercise of the capacity should not plausibly be construed

\footnotetext{
9 Even if they do not do so for us, there are possible agents for whom that can be the case. The reader should easily be able to think of examples.
} 
in a way where instrumental rationality necessarily applies to it. If that is the case, there is no reason for us to connect the capacity to set ends to us having knowledge of our circumstances. Aiming to make use of the capacity to set ends rationally need not have anything to do with aiming to do so in a way that makes instrumental rationality apply.

The reason we need not connect a capacity of instrumental rationality to the exercise of the capacity to set ends is that the capacity to set ends need not be exercised in action or conscious deliberation. Sometimes we set our ends actively and through deliberation. But often we form plans or intentions without any prior aim of doing so. For example, if I am walking down the street and I see a venomous snake on the pavement in front of me, I do not need to deliberate or perform any other action to make a decision to walk somewhere where I avoid it. I just form the plan or intention to walk elsewhere than in its path. ${ }^{10}$

Because of the non-conscious way in which I form my intention here, a principle of instrumental rationality need not have any bearing on the exercise of the capacity to form the end. On a rough yet standard formulation, instrumental rationality regulates the relation between my ends and means; if I aim (desire or intend) to $\varphi$, and I believe $\psi$ is a necessary means to $\varphi$, I am irrational if I do not (or do not desire or intend) to $\psi$. But one need not aim to exercise one's capacity for intention-formation to exercise it - it is just not the sort of thing that one needs to aim at exercising to exercise. Hence, it seems like a category mistake to connect instrumental rationality to the capacity to set ends. While we may aim to set ends, we need not do so.

Now to premise (4). It reads: 'An environment secured against intervention by unpredictable, powerful forces uniquely facilitates the acquisition of knowledge concerning causal regularities and concerning the disposition of items in the environment.' The premise is hard to interpret - what is an 'environment', for example, let alone a 'secure' one? What does it mean for a force to be 'unpredictable' or 'powerful'? Regardless of how we should interpret the details, however, the core idea here is that knowledge of an environment will be uniquely facilitated by its being secured against the intervention of unpredictable, powerful forces. As per the discussion of (4) above, Fichte and Kosch are worried about how hard it is to acquire knowledge in insecure environments. Instead, they think that such knowledge is 'uniquely facilitated' if the environment is secured against unpredictable, powerful forces. However, I shall present three counterexamples to the premise. The first two apply to any plausible interpretation of what counts as an environment. The third assumes, I

\footnotetext{
${ }^{10}$ Why could that intention not be formed because of some non-occurent or backgrounded intention to avoid venomous snakes that I already have, which I in turn have formed due to an action? There can be such cases - if I have travelled somewhere where I risk encountering venomous snakes, I may well have formed a conditional intention about what to do if I were to encounter one prior to walking down the street. But there are also cases where I have not considered that option. Perhaps I am walking down the street in an area where no venomous snakes ordinarily live, but the one I encounter has just been dropped from a helicopter passing by. It would be unreasonable to expect people to have deliberated about what to do on such occasions.
} 
think rightly, that the environments themselves sometimes can include powerful and unpredictable forces. The cases add up to two main problems. ${ }^{11}$

First, the premise seems false. I grew up close to wild nature. There were several large animals that I sometimes could spot in the woods in the area - lynx and moose, for example. But I was under no threat of natural disasters like tsunamis. Assume, however, that everything would have been the same except that the area would suffer from tsunamis every now and then (without anyone knowing exactly when they would occur, so they would still count as unpredictable). Why would the risk of tsunamis affect my - or a team of scientists' - ability to observe the mammals in the area? Perhaps I (or they) would not get out into the local forest as often to observe them if there had been a risk of tsunamis. But we should still easily be able to get out often enough to observe the animals and learn many interesting things about them. It would take a very extreme environment for us to not be able to observe the animals every now and then.

Hence, premise (4) seems inflated. Environments at risk of suffering from the effects of unpredictable, powerful forces of nature can be secure enough for gathering knowledge. Therefore, secure environments do not 'uniquely facilitate' the knowledge Fichte thinks agents need.

But there is an even greater problem for (4). Insecure environments often seem better at providing us with knowledge about causal regularities or the dispositions of items in them than secure ones do. There are two kinds of counterexample cases that support this conclusion. First, the causal regularities or dispositions might be hard to systematize. Assume again that we are trying to learn something about the behaviour of the local fauna. But assume also that the local fauna is able to behave in many different ways. We may then very well learn more about its behaviour in an insecure environment than in a secure one, for the insecure environment may elicit more behaviours from the animals. Birds that ordinarily nest in treetops may start to nest on the ground if a tsunami has knocked all the trees over, for example. Secure environments would not facilitate knowledge of nesting behaviour under such conditions.

In the light of the second kind of cases, premise (4) even risks being self-defeating. As Kosch does not say what an 'environment' is supposed to be, I shall make an assumption: an environment can include unpredictable, powerful forces. This seems plausible enough - if whatever is in an environment is a part of it, and tsunamis are in some environment, they are part of it. But if so, we can learn a lot about environments that include unpredictable and powerful forces, including things about those forces themselves, because they intervene in the environment. It is hard to predict everything of interest about how a tsunami may impact us, but we may learn more by observing what impact it has on us after it has had an impact. Hence, securing an environment from unpredictable, powerful forces risks giving us less knowledge of the environment than if it had been insecure, generating a kind of self-defeat.

11 One could even think of them as elaborations of Kosch's arguments for why (4) should be formulated in terms of 'unique facilitation'. But the problems go deeper than she appears to presume. 
I conclude that premise (4) is unworkable. We can often gain as much knowledge of an environments when it is subject to unpredictable, powerful forces as when it is secured from them. In many cases, we can even gain more knowledge of it when such forces affect it.

Could Fichte say anything about this? In Kosch (2015), Kosch presents a much weaker version of the argument above. It looks like this:

(1') An agent with an interest in the exercise of her capacity rationally to set ends ought (ceteris paribus) to have an interest in the obtaining of any conditions necessary for the exercise of that capacity.

(2') (Relevant) knowledge is a condition necessary for the exercise of the capacity rationally to set ends.

(3') Control of (some part of) the environment is a necessary condition of (relevant) knowledge.

(C') An agent with an interest in the exercise of her capacity to set ends ought (ceteris paribus) to have an interest in control of (some part of) her environment.

Fichte could accept (3') instead of (4), and then try reformulate the rest of the argument by appealing to control of one's environment rather than security from 'unpredictable, powerful forces.' But I doubt this would help much. The tsunami cases should easily be able to show us that control is not a necessary condition for knowledge. Hence, versions of the counterexamples I just presented for (4) reappear here, mutatis mutandis. Fichte's argument seems over by premise (4).

\section{The Fichtean Lesson}

I have now criticized premises (1) and (4) in Fichte's argument. As mentioned, I think (1) can be reformulated, but the arguments against (4) are decisive. This takes us to the constructive part of the paper. Its aim is, after all, to make use of Fichte's insights in the context of reasons internalism. With his line of thought presented and evaluated, it is now time to do just that. I shall start off by reformulating (1). But to do that, I shall first introduce desire-based reasons internalism in greater depth.

Desire-based reasons internalism, as I understand it, says that our reasons depend on our desires. Here we may make a distinction. Either reasons depend on an agent's actual desires or on her ideal desires. I will help myself to the ideal desires view here and make use of it in the rest of my argument as it is the one I prefer (Leffler, 2016; 2019; 2020). ${ }^{12}$ A rough definition is the following (cf. Leffler, 2019; 2020):

\footnotetext{
12 On Schroeder's influential 2007 view, things might look different here. For Schroeder, roughly, any fact which is conducive to the satisfaction of an agent's desires is a reason. Being such that one has a lot of knowledge is presumably conducive to that, so he seems to get the reason I want to defend very easily.
} 
(IDEAL DESIRES INTERNALISM) For all $r(F, A, \alpha, C), r(F, A, \alpha, C)$ is a reason relation holding between a fact $F$ and an agent $A$ 's action $a$ in circumstances $C$ iff (and because) $r(F, A, \alpha, C)$ holds in virtue of the desires that feature in $P$ 's idealized psychology.

Here, I do not concern myself with the exact interpretation of metaphysical details like what a fact, a desire, an action, or the 'in virtue of'-relation are, though I shall use the conventional terminology of grounding for the latter for simplicity (Chang, 2013). I shall, however, say something more about how $A$ and $C$ work.

First, what does 'the desires that feature in $P$ 's idealized psychology' mean? Like most ideal desires internalists, I shall assume that the agent whose desires explain reasons has desires, beliefs, and is suitably rational. Desire-based reasons internalism need not be committed to the Humean theory of motivation, but it is still presumed that agents generally act in virtue of the features of this kind of psychology. Moreover, the mental states of ideal agents are idealized - idealization plays a role in ensuring us that the desires we have are those that plausibly can explain reasons. I shall follow convention and call the relevant fully idealized agents ' $A+$ ', while nonidealized ones remain called ' $A$ ' below. $A+$ is a hypothetical idealized version of $A$, but like $A$ in all other respects.

What does the idealization of $A+$ involve? Philosophers unsurprisingly adduce different conditions, but there is wide agreement on at least the following ones:

(i) $A+$ is rational, in some sense of rationality. Most internalists interpret this demand weakly, referring to internal coherence, though there are also some stronger interpretations (cf. Jian, 2021).

(ii) A+'s psychology is fit for its purpose. For example, if the agent's mental states are given a functionalist interpretation, she is not supposed to have a psychology where her functionality is impaired.

(iii) $A+$ has the right psychology to explain reasons, such as some set of true beliefs or knowledge (Williams, 1981; Smith, 1994), or even special desires (Leffler, 2020; Smith, 2011; 2012; 2020). ${ }^{13}$

I shall assume that some versions of (i)-(iii) hold for ideal agents, and that it is ideal desires based on these conditions that ground A's reasons. With IDEAL DESIRES INTERNALISM now presented, we can use the assumptions behind $A+$ to develop Fichte's ideas. I shall start by developing premise (1) in his argument into (1*):

$\left(1^{*}\right)$ If an agent is an ideal agent with a possibly varying set of desires, the agent ought to desire to obtain or maintain any conditions necessary for acting on its possibly varying desires.

The major shift from (1) here is that I talk about a possibly varying set of desires rather than a capacity to set ends that an agent may exercise. This reflects how desires feature in IDEAL DESIRES INTERNALISM. Ordinary agents sometimes

\footnotetext{
13 The former has sometimes been called an assumption of rationality (e.g. Smith, 1994, ch. 5). Kosch does this too (2018, p. 24), but I think it is too strong for that.
} 
change their desires in the light of new experiences, reasoning, etc., and ideal agents do so as well, not least as a matter of their idealization (as I shall argue below). ${ }^{14}$ Moreover, I have changed 'aim to obtain or maintain (...)' to 'desire to obtain or maintain (...).' This change is also implied by IDEAL DESIRES INTERNALISM, for there aims are conceived of as desires. For simplicity, I have also formulated the premise as a conditional and removed the ceteris paribus-clause, as it is unclear how we should spell out which conditions are equal or not - but the reader is free to read $(1 *)$ with one if she so wishes.

With the clarifications in place, the core idea in $\left(1^{*}\right)$ is that ideal agents ought to desire to obtain or maintain any conditions necessary for acting on their possibly varying desires - including those of possible desires that they do not currently have. I emphasize 'possibly varying' desires here because the desires of ideal agents are highly variable. They are set up to go through new experiences, reason, use their imagination, etc., which enables their desires to change. This is because the point of idealization is that they are supposed to acquire desire sets that ground reasons, and non-ideal desire sets often fail to do that. ${ }^{15}$

This means that an ideal agent's desire set can vary, but with a highly varying set of desires, it is likely that the ideal agent will end up in situations where they cannot act on their desires. Perhaps they are in circumstances where other agents will stop them from acting on their desires, or perhaps they do not have the knowledge necessary for satisfying them. But the ideal agent should be such that their actions could be driven even by their possibly varying desires. This is because acting on their possible desires is likely to have further effects on A+'s desire sets, and therefore also on the reasons of non-ideal agents. Hence, ideal agents who are not in the right conditions to act on their possibly varying desires fail to live up to condition (iii) above. As their desire sets are likely to be altered by acting on their possibly varying desires, they do not have the right psychologies if they do not. ${ }^{16}$

Why? As L.A. Paul has stressed, the first-personal experience of many kinds of events is likely to alter someone in unpredictable ways. One is likely to go through transformative experiences (Paul, 2014). Maybe some of A+'s desires become strengthened or weakened if they act on them, maybe acting on some desires will give them important knowledge of the experience of acting on them, or maybe $A+$

\footnotetext{
${ }^{14}$ It is conceivable that there are non-ideal agents the desires of which cannot possibly change, in some sense of possibility, but it is possible for ideal agents to change their desires in any relevant sense of possibility, whatever it might be, as that is necessary for idealization to work. I want to thank an anonymous reviewer for pushing me to clarify this.

15 Consider, for example, the famous case of someone who desires to drink a glass of petrol rather than a glass of gin because they do not know what the glass contains (Williams, 1981).

16 Does this argument imply that the ideal agent ought to have desires for pretty much everything and act on them all, as potentially all courses of action and knowledge might affect their desire set? Maybe, but my formulation is less ambitious. I have not specified which alterations might matter, and possibly these are limited by the agent's present desires. If neither $A$ nor $A+$ care one iota about 80 s cartoons, it is hard to see how watching them would necessitate any relevant effects.
} 
might form or lose some desires. These effects matter for which reasons $A$ has based on $A+$ 's desires. ${ }^{17}$

Assume that $A$ has a desire to go to university but does not know what to study. As $A$ learns more about philosophy, $A$ considers studying it to the $\mathrm{PhD}$ level - but whether $A$ has reason to study it depends on $A+$ 's desires, not on $A$ 's present desires. However, if $A+$ were to go to grad school, $A+$ could find their desire for philosophy becoming stronger or weaker with the experience of doing so or find that they have new knowledge of what it is like to do a PhD after having done it. This knowledge could even impact whether they find philosophy enjoyable or inspire some other desire. Perhaps $A+$ enjoys brainstorming but not conference presentations, so they form a desire to engage in a line of work where they would get to brainstorm more but go to conferences less. These desires on $A+$ 's parts will determine $A$ 's reasons - but $A+$ could not have formed them without going to grad school in philosophy. They are based on the transformative experiences of going there. Just imagining what it is like to go there says little about what it it $i s$ like to do so, so $A+$ needs to go there rather than just imagine what it is like.

All this holds even if going to grad school is not something that $A$ or $A+$ had been able to do at the start of the idealization process. $A$ is setting out to go to university, and is not likely to have the knowledge necessary for a $\mathrm{PhD}$ in philosophy. But if so, not having the relevant conditions in place for acting on their possibly varying desire to go to grad school in philosophy entails that they could not have access to experiences necessary to attain the right desires to explain $A$ 's reasons. So $A+$ needs the right background conditions.

$A+$ should, then, desire to obtain or maintain the relevant necessary conditions rather than just be in them. This is because she is like the non-ideal agent in all respects except those in which she is idealized. Because ideal agents are in many ways like ordinary human agents, the conditions necessary for acting on the varying set of desires may have to be acquired, or they may be lost. For example, they may have learned or forgot relevant knowledge - just think of what is necessary to get into grad school in the first place. However, with a desire to maintain or obtain the conditions necessary for acting on their possibly varying desires, the ideal agent will be motivated to possess them even when they lack them or could lose them. So a desire to obtain or maintain the conditions necessary for acting on their possibly varying desires would ensure their being ideal. Hence, they need the desire - so $\left(1^{*}\right)$ is defended.

My formulation of the premise can also avoid the problems I presented for Fichte's (1). The first problem is the overintellectualization involved in taking agents to be constituted by Fichte's capacity to set ends. But I have, instead, talked about the desires of ideal agents. From the formulation of reasons internalism, an agent

\footnotetext{
17 Some have argued against IDEAL DESIRES INTERNALISM by appealing to how desires may change in problematic ways when agents become idealized (e.g. Gibbard, 1990; Sobel, 2001; cf. also references related to 'the conditional fallacy' in fn. 19). Those arguments do not convince me, but discussing the issue in depth is outside the scope of this paper. My argument here just needs the point that first-personal experience can affect desires in a way which affects reasons, and that claim is plausible whatever one makes of this debate.
} 
already has a set of desires, and the one defended here is added for the sake of proper idealization. There is no end-setting capacity involved here.

The second problem for Fichte is that there seems to be an illicit use of instrumental rationality in his (1). Instrumental rationality does, in general, not need to have anything to do with making use of the capacity to set ends. However, we can defend $\left(1^{*}\right)$ by appealing to the notion of ideal agency rather than with instrumental rationality, for both ideal and ordinary agents can act based on their desires on the conception of agency typically defended by reasons internalists.

We can, then, also reformulate (2) to $(2 *)$ :

$(2 *)$ If the agent ought to desire to obtain or maintain any conditions necessary for acting on her possibly varying desires, then she ought to desire to obtain knowledge concerning causal regularities and concerning the disposition of items in the environment.

$(2 *)$ has also been reformulated into a conditional, but I do not think it needs much more defence. Kosch's argument for (2) premise seems plausible to me, but I can also adduce a much less controversial consideration in favour of $\left(2^{*}\right)$ than she did for $(2)$, hence yielding a stronger defence of $(2 *)$.

More specifically, I can appeal to variability again. As $A+$ 's desire set may change in idealization, $A+$ seems in need of a significant amount of knowledge about her surroundings to act on many different possible desires that may be acquired in that process. Knowledge about many possible means and outcomes is a necessary condition for acting on many potential desires. Hence $(2 *)$ seems plausible, whatever one thinks of Kosch's defence of it.

Some more clarification could help here. First, we are talking about real knowledge here, regardless of how we interpret knowledge. The argument from variability does not, therefore, indicate that $A+$ has a pragmatic reason to believe what would satisfy their or A's desires. They may have such a pragmatic reason, but that is not what I am arguing. Rather, they should desire to obtain or maintain knowledge.

Second, Kosch claims that she can run her argument by appealing to true belief rather than knowledge, as that may be enough for action (cf. fn. 8 above). This might work, but formulating (2) or (2*) in terms of 'true beliefs' seems too concessive. This is because differentiating between, and asking about the relative values of, true belief and knowledge here is to raise the Meno problem in the context of true beliefs about means to take to satisfy one's possibly varying desires. One is essentially asking 'Why does knowledge matter more than true belief?'. That question is far too big to settle here. However, because knowledge (and not just true belief) typically is taken to be the paradigmatic mental state reflecting the world, I shall, more boldly just write as if what matters here is knowledge rather than mere true belief.

With $\left(1^{*}\right)$ and $\left(2^{*}\right)$ in place, we get the following argument:

(1*) If an agent is an ideal agent with a possibly varying set of desires, the agent ought to desire to obtain or maintain any conditions necessary for acting on her possibly varying desires.

$(2 *)$ If the agent ought to desire to obtain or maintain any conditions necessary for acting on her possibly varying desires, then she ought to desire to obtain 
knowledge concerning causal regularities and concerning the disposition of items in the environment.

( $\left.3^{*}\right)$ If an agent is ideal agent with a possibly varying set of desires, then she ought to desire to obtain or maintain knowledge concerning causal regularities and concerning the disposition of items in the environment.

$A+$ ought then to form this desire. She would not have the right mental states for being ideal if she did not. More specifically, she ought to form - and therefore has, in virtue of being ideal - a desire to obtain or maintain knowledge concerning causal regularities and concerning the disposition of items in the environment. In short, she ought to desire to obtain or maintain knowledge about her surroundings.

The upshot here is big. Using the basic conceptual move of IDEAL DESIRES INTERNALISM, with $\left(3^{*}\right)$, we can generate a reason for actual agents to attain knowledge of their surroundings. As $A+$ 's desires ground $A$ 's reasons, it follows that if $A+$ has a desire to obtain or maintain knowledge about the environment, $A$ has a reason to obtain or maintain such knowledge. As IDEAL DESIRES INTERNALISM is a theory of reasons for action, this is a reason to learn relevant things and to make sure that one does not forget them, not a reason for belief. ${ }^{18}$

Just how we have that reason does, however, vary with different forms of IDEAL DESIRES INTERNALISM. There are two main versions (Smith, 1995). ${ }^{19}$ One treats the ideal agent as an exemplar. On that view, roughly, $A$ has reason to $\varphi$ if $A+$ desires to $\varphi$ in any given case. If so, $A$ has a reason to obtain or maintain knowledge to the extent that $A+$ desires to do so.

Alternatively, one may treat the ideal agent as an advisor, where the idea is that $A$ 's reasons to $\varphi$ depend on what $A+$ would advise $A$, qua actual agent, to do. If so, roughly, $A$ has a reason to $\varphi$ in $C$ just in case $A+$ would advise them to $\varphi$. This reason will remain categorical in the sense that all $A+$ 's will have the same desire and therefore advise $A$ to obtain and maintain knowledge at some points, but just when $A+$ would advise $A$ to attain such knowledge is an additional question. Fortunately, it is not one that needs to be settled here. It is extremely likely that $A+$ sometimes would advise $A$ to learn more about the world in the light of $A+$ 's desire to do so. How else would $A$ be able to take means to her ends, not least given that $A$ 's own desires could vary over time?

There is an important worry here, however. As ideal agents are ideal, we may wonder why they would need desires to obtain or maintain knowledge in the first place. Perhaps they already have all relevant knowledge, and hence the desire is unnecessary? When I defended ( $\left.1^{*}\right)$ above, I argued that because ideal agents are in many ways similar to ordinary human agents, the conditions necessary for action

\footnotetext{
18 It might, however, look similar to reasons for belief according to instrumentalists about epistemic reasons (e.g. Cowie, 2014; Kornblith, 2002). Their idea is that $R$ is a reason to believe that $p$ because $R$ improves the satisfiability of our desires. However, the reason to know is just a practical reason to learn or remember important things - it does not say anything about epistemic reasons.

19 The debate between them is vexed (cf. e.g. Johnson, 1997; 1999; Tubert, 2016; Wiland, 2000; 2003). I prefer the advisor view.
} 
can be gained or lost. But maybe knowledge cannot. It is often thought to be the kind of mental state that we just should assume ideal agents have (cf. condition (iii) in the characterization of IDEAL DESIRES INTERNALISM above).

However, like ordinary agents, ideal agents are able to gain or lose their knowledge, so knowledge should be treated like other kinds of necessary conditions for acting on possibly varying desires. This means that because they may gain or lose it, they ought to desire it rather than just have it. They may, for example, either risk forgetting or actually forget something important. But a desire to know would motivate them to obtain or maintain the knowledge in question. With relevant (and sufficiently strong) desires, they would remember or re-learn important things.

Why should we treat knowledge as similar to other conditions rather than something ideal agents always necessarily have? I have stressed above that the ideal agent should be treated as similar to a real agent, idealization aside. But the idealization of the ideal agent does not imply that they always are in ideal circumstances themselves. They need to be able to, for example, exist in a world where a strong blow to the head could make them risk forgetting or actually forget what they know. That experience could by itself be transformative, just like the experience of various actions, including that of going to grad school in philosophy. Therefore, the firstpersonal experience of a blow to the head will matter for explaining the reasons of $A$ 's reasons (and not least if $A$, too, has undergone such a blow to the head) - the shape of $A+$ 's desire set is likely to be altered by experiencing the blow, forgetting important things, and then relearning them. Hence, just taking $A+$ to always have the right knowledge makes them too ideal, but the desire will explain how they can be ideal in the right way.

\section{What Kind of Reason?}

I have now defended the claim that IDEAL DESIRES INTERNALISM is committed to a reason to obtain or maintain knowledge. What kind of reason is that? I have mentioned above that I take the reason to be categorical. It is categorical in the sense that ( $i$ ) qua reason, it has normative force (because if any practical reasons have, this one has too), and (ii) all agents have it (because all their idealized counterparts whose desires ground reasons have it). The kind of categoricity at work here is defended by Smith (1994, ch. 5), and Joyce (2001) also uses it in his reasons internalist argument for an error theory about morality. As such, it is a standard reasons internalist way to think of categoricity, and one which this reason satisfies.

Is it also a moral reason? This is not the place to determine what makes a reason a moral reason, but we can evaluate whether the reason to know counts as one according to the leading accounts of what it is to be a moral reason in the literature. There are at least four different ways to explicate that distinction - or, alternatively, one may deny that there is a distinction. ${ }^{20} \mathrm{I}$ shall argue that these

\footnotetext{
${ }^{20}$ Potentially, one could also combine some of the four ways of explicating it into more complex accounts. But the problems for the less complex account would then carry over to the complex ones.
} 
accounts often give unclear or conflicting verdicts regarding the reason to obtain or maintain knowledge that I have suggested. The upshot is that we do not know whether the reason to obtain or maintain knowledge is a moral reason.

I follow Forcehimes \& Semrau (2018) in distinguishing between different accounts of the relation between moral and non-moral reasons. The first view they consider is:

(PLURAL GROUNDS) There are reasons of fundamentally different kinds, which differ with respect to their ultimate grounds. The ultimate grounds of moral reasons are distinguishable from the ultimate grounds of non-moral reasons. (Forcehimes \& Semrau, 2018, p. 701)

There are two versions of this view. The first is due to Southwood (2011). Here, reasons that are based on social grounds are non-moral, whereas those that are based on non-social grounds are moral. Clearly, the reason to obtain or maintain knowledge is moral on that view - it has nothing to do with sociality.

Second, they consider a Kant-inspired view according to which categorical reasons are moral, but non-categorical ones are not. The reason to gain knowledge seems straightforwardly categorical - I just argued that it was - and hence moral here. However, the reason to know one's surroundings is not categorical on this view if categoricity is taken to mean something else than that the reason is applicable to all relevant agents, like reasons internalists might think. Perhaps one thinks that a categorical reason is one that is based on a desire-independent value. As such, there is still some unclarity about what it should count as here. A defender of the Kantian view would have to say more about what categoricity means for us to be able to see whether the reason to obtain or maintain knowledge counts as categorical and therefore moral.

Forcehimes and Semrau also consider content-based views of the distinction between moral and non-moral reasons. First, they discuss views about reasons according to which 'moral reasons share, while non-moral reasons lack, an intimate connection to responsibility. This connection, in contemporary guise, links moral reasons to reactive attitudes such as praise, blame, and indignation' (Forcehimes \& Semrau, 2018, p. 707). Second, they discuss views according to which moral reasons are other-regarding, whereas non-moral reasons are self-regarding (Forcehimes \& Semrau, 2018, pp. 710-715).

It is hard to know what to make of the connection to responsibility. Are we responsible for acquiring knowledge about our circumstances so we can act? Maybe. Innocence may or may not be criticizable. Someone who lacks knowledge of the evils of the world might seem to be outside the responsibility game altogether. But, simultaneously, naïve agents who do not know what they need to know often seem more than criticizable for that very reason.

Unfortunately, this issue gets messier still, for it is not clear in what sense someone who lacks knowledge is criticizable. It seems eminently plausible to think that there can be distinctly epistemic senses of praise, blame, and indignation, and these need not be related to our moral evaluations. Even if it is epistemically blameworthy to fail to proportion one's belief to the evidence, it would still have been morally praiseworthy to do so if that would have prevented WWII. As 
such, the responsibility view requires significant additional explication to indicate much.

The other-directedness view is, however, clearer. The reason to generate knowledge is not other-directed, so if that is how one thinks of moral reasons, it is not a moral reason. This criterion, therefore, stands in conflict with (at least) the PLURAL GROUNDS views, according to which the reason to obtain or maintain knowledge does seem moral (at least at first glance).

I have now considered the views distinguished by Forcehimes \& Semrau. On PLURAL GROUNDS views, the reason to know seems to be a moral reason. The responsibility view, it is unclear whether it is one. And on the other-regardingness view, it does not seem to be one. As such, it is quite unclear whether we should think of the reason to know one's surroundings as a moral reason - whether we should do so or not depends on where we go on the moral/non-moral distinction.

However, one could also think that there is no real distinction between moral and other (practical) reasons. On this view, practical reasons are just practical reasons. Nothing makes a reason a moral reason rather than a non-moral reason: the distinction is superfluous. But if so, the reason to know could still hardly qualify as distinctively moral because there are no distinctively moral reasons in the first place. Hence, we cannot count the reason to know as a distinctively moral reason on the view where there is no difference between moral and other practical reasons either. Of course, we cannot count it as a distinctively non-moral reason either, because there are, simultaneously, no such reasons. But that is neither here nor there. It is not a distinctively moral reason, because on this view, there are no such reasons.

\section{Conclusion}

In this paper, I have argued that ideal desire internalists are committed to at least one categorical reason for action, namely, a reason to obtain or maintain knowledge of our surroundings. I first presented Kosch's Fichte, but then criticized Fichte's argument at some length. However, I plugged some Fichtean insights into IDEAL DESIRES INTERNALISM and defended a categorical reason to obtain or maintain knowledge of one's surroundings. I also argued that is it highly unclear whether this reason should count as a moral reason. This means that desire-based reasons internalism seems committed to more than one previously might have expected.

The reason to know also gives rise to interesting theoretical possibilities. I have not addressed the question of whether there might be other categorical reasons that could be defended in the same way as the reason to know above. It would be intrinsically interesting to inquire into whether any could be - and making sense of them might even have other theoretical payoffs downstream. It has often been argued that desire-based reasons internalism is implausible because it might imply that agents have too few or too many reasons if they desire the wrong things. But if ideal agents are committed to the right desires, perhaps that worry can be ameliorated. For now, however, these are possibilities for future research. This paper has defended a categorical reason to know. 
Open Access This article is licensed under a Creative Commons Attribution 4.0 International License, which permits use, sharing, adaptation, distribution and reproduction in any medium or format, as long as you give appropriate credit to the original author(s) and the source, provide a link to the Creative Commons licence, and indicate if changes were made. The images or other third party material in this article are included in the article's Creative Commons licence, unless indicated otherwise in a credit line to the material. If material is not included in the article's Creative Commons licence and your intended use is not permitted by statutory regulation or exceeds the permitted use, you will need to obtain permission directly from the copyright holder. To view a copy of this licence, visit http://creativecommons.org/licen ses/by/4.0/.

\section{References}

Brunero, J. 2017. Recent Work on Internal and External Reasons. American Philosophical Quarterly. 54 (2): 99-118.

Bukoski, M. 2016. A Critique of Smith's Constitutivism. Ethics 127 (1): 116-146.

Chang, R. 2013. Grounding Practical Normativity: Going Hybrid. Philosophical Studies. 164 (1): $163-187$.

Cowie, C. 2014. In Defence of Instrumentalism about Epistemic Normativity. Synthese 191 (6): 4003-4017.

Fichte, J.G. 1798. The System of Ethics. [any edition].

Forcehimes, A., and L. Semrau. 2018. Are There Distinctively Moral Reasons? Ethical Theory and Moral Practice. 21 (3): 699-717.

Gibbard, A. 1990. Wise Choices, Apt Feelings: A Theory of Normative Judgment. Cambridge, MA: Harvard University Press.

Hubin, D.C. 1999. Converging on Values. Analysis 59 (264): 355-361.

Jian, J. 2021. Misinformation, Subjectivism, and the Rational Criticizability of Desire. Philosophical Studies. 178 (3): 845-866.

Johnson, R.N. 1997. Reasons and Advice for the Practically Rational. Philosophy and Phenomenological Research. 57 (3): 619-625.

Johnson, R.N. 1999. Internal Reasons and the Conditional Fallacy. Philosophical Quarterly. 49 (194): 53-72.

Joyce, R. 2001. The Myth of Morality. Oxford, UK: Oxford University Press.

Katsafanas, P. 2013. Agency and the Foundations of Ethics: Nietzschean Constitutivism. Oxford, UK: Oxford University Press.

Katsafanas, P. 2018. Constitutivism About Practical Reasons. In Oxford Handbook of Reasons and Normativity, ed. D. Star, 367-391. Oxford, UK: Oxford University Press.

Kornblith, H. 2002. Knowledge and Its Place in Nature. Oxford, UK: Oxford University Press.

Kosch, M. 2015. Agency and Self-Sufficiency in Fichte's Ethics. Philosophy and Phenomenological Research. 91 (2): 348-380.

Kosch, M. 2018. Fichte's Ethics. Oxford, UK: Oxford University Press.

Leffler, O. 2016. The Foundations of Agency - and Ethics? Philosophia 44 (2): 547-563.

Leffler, O. 2019. The Constitution of Constitutivism, PhD Dissertation, University of Leeds, UK.

Leffler, O. 2020. Reasons Internalism, Cooperation, and Law, in Social Ontology, Normativity, and Law, ed. M. Garcia-Godinez, R. Mellin and R. Tuomela, 115-132. Berlin, GER: de Gruyter.

Lindeman, K. 2019. Functional Constitutivism's Misunderstood Resources: A Limited Defense of Smith's Constitutivism. Ethics 130 (1): 79-91.

Markovits, J. 2014. Moral Reason. Oxford, UK: Oxford University Press.

Nagel, T. 1970. The Possibility of Altruism. Princeton, NJ: Princeton University Press.

Parfit, D. 1984. Reasons and Persons. Oxford, UK: Oxford University Press.

Paul, L.A. 2014. Transformative Experience. Oxford, UK: Oxford University Press.

Schroeder, M. 2007. Slaves of the Passions. Oxford, UK: Oxford University Press.

Smith, M. 1994. The Moral Problem. Oxford, UK: Blackwell Publishing.

Smith, M. 1995. Internal Reasons. Philosophy and Phenomenological Research. 55 (1): 109-131.

Smith, M. 2011. Deontological Moral Obligations and Non-Welfarist Agent-Relative Values. Ratio 24 (4): 351-363. 
Smith, M. 2012. Agents and Patients: Or, What We Learn about Reasons for Action by Reflecting on Our Choices in Process-of-Thought Cases. Proceedings of the Aristotelian Society 112 (3): 309-331.

Smith, M. 2020. The Modal Conception of Ideal Rational Agents: Objectively Ideal Not Merely Subjectively Ideal, Advisors not Exemplars, Agentially Concerned Not Agentially Indifferent, Social Not Solitary, Self-and-Other Regarding Not Wholly Self-Regarding. In Explorations in Ethics, ed. D. Kaspar, 59-79. New York, NY: Palgrave Macmillan.

Sobel, D. 2001. Explanation, Internalism, and Reasons for Action. Social Philosophy \& Policy 18 (2): 218-235.

Southwood, N. 2011. The Moral/Conventional Distinction. Mind 120 (479): 761-802.

Street, S. 2008. Constructivism about Reasons. In Oxford Studies in Metaethics, vol. 3, ed. R. ShaferLandau, 207-245. New York: Oxford University Press.

Tubert, A. 2016. Sound Advice and Internal Reasons. Pacific Philosophical Quarterly. 97 (2): 181-199.

Wiland, E. 2000. Good Advice and Rational Action. Philosophy and Phenomenological Research. 60 (3): 561-569.

Wiland, E. 2003. Some Advice for Moral Psychologists. Pacific Philosophical Quarterly. 84 (3): 299-310.

Williams, B.A.O. 1981. Internal and External Reasons. In Moral Luck: Philosophical Papers 1973-1980, ed. B.A.O. Williams, 101-113. Cambridge, UK: Cambridge University Press.

Publisher's Note Springer Nature remains neutral with regard to jurisdictional claims in published maps and institutional affiliations. 